\title{
El concepto de autoridad en el pensamiento de Aristóteles y su relación con el concepto de autoridad en el comportamiento administrativo
}

Luis Antonio Cruz Soto Investigador, Facultad de Contaduría y Administración, UNAM lcruz@correo.fca.unam.mx

\section{Resumen}

En este trabajo se analiza el concepto de autoridad en el pensamiento de Aristóteles y su relación con el concepto de autoridad en el comportamiento administrativo. Para ello, desarrollamos dos apartados: en el primero analizamos el concepto de autoridad en Aristóteles con el fin de definir los elementos de estudio que nos permitan vincularlos con el concepto de autoridad en el comportamiento administrativo; en el segundo establecemos el significado de la autoridad en el comportamiento administrativo para determinar la relación conceptual entre éste con el concepto de autoridad en el pensamiento de Aristóteles. En este trabajo sostenemos que la legitimidad define el concepto de autoridad en Aristóteles y en el comportamiento administrativo, con lo que asumimos que el carácter legítimo de la dominación aspira al reconocimiento racional de los individuos frente a los mandatos y, al mismo tiempo, genera procesos de validez funcional mediante la pertinencia de las disposiciones que surgen de los mismos. Finalmente, concluimos que la autoridad en Aristóteles y la autoridad en el comportamiento administrativo se orientan por la legitimidad a partir del reconocimiento informado, racional y voluntario de los dominados que se sustenta en la función.

Palabras clave: autoridad, legitimidad, dominación, función. 


\title{
The concept of authority in the thinking of Aristotle and its relationship with the concept of authority in the administrative behavior
}

\begin{abstract}
This paper analyzes the concept of authority in the thinking of Aristotle and its relationship with the concept of authority in the administrative behavior. Thus, we develop our arguments in two main parts: in the first one we analyze the concept of authority from the Aristotle's view in order to define the elements of study that allow us to link such elements with the concept of authority in the administrative behavior; in the second part, we build the meaning of the authority in the administrative behavior to determine its conceptual relationship with the concept of authority in the Aristotelian thought. We hold that the concept of authority is defined by the legitimacy both in the view of Aristotle as in the view of the administrative behavior. Therefore, we assume that the legitimacy of the domination: a) seeks the rational recognition by the actors that are facing the content of the mandates and, b) at the same time, it generates processes of functional validity through the relevant provisions arising from those mandates. We conclude that the authority, be it in the Aristotelian sense or in the sense of the administrative behavior, is guided by the legitimacy which in turn is based on recognition — informed, rational and voluntary — from the perspective of the individuals who are dominated.
\end{abstract}

Keywords: authority, legitimacy, domination, function.

\section{Introducción}

El objetivo de este trabajo consiste en analizar el concepto aristotélico de la autoridad y su relación con el concepto de autoridad en el comportamiento administrativo ${ }^{1}$. Este artículo se divide en dos apartados; en el primero se analiza el concepto de autoridad en el pensamiento de Aristóteles; y en el segundo, se establece el vínculo entre el concepto de autoridad de Aristóteles y el concepto de autoridad en

\footnotetext{
${ }^{1}$ En este trabajo entenderemos por comportamiento administrativo la manifestación colectiva de un grupo de individuos que responde a un mismo estímulo o situación afín dentro de una organización (Vid., Gallino, 1995: "Comportamiento colectivo"). El comportamiento de los individuos se refiere a una selección, consciente o inconsciente, de determinadas acciones que sirven a un propósito definido. Herbert Simon señala que el comportamiento administrativo es intencionado, es decir, está orientado hacia metas u objetivos, lo que trae como consecuencia una integración en el modelo de comportamiento, sin la cual la administración carecería de sentido, pues si la administración la entendemos como "conseguir que se hagan las cosas" por grupos de personas, entonces la finalidad proporciona un primer criterio para determinar las cosas que hay que hacer (Simon, 1979: 5-6). El comportamiento administrativo es la confluencia relativamente ordenada de actitudes individuales relativas a la realización de procedimientos administrativos con un propósito definido. En este artículo empleamos el
} 
el comportamiento administrativo. En este artículo sostenemos que lo que define a la autoridad es la legitimidad ${ }^{2}$, con lo que se establece la relación conceptual entre el significado de la autoridad que señala Aristóteles y lo que se comprende como autoridad en el comportamiento administrativo, en el sentido de que quienes ejercen la dominación ${ }^{3}$ legítima tienen ante sí la posibilidad de validar su actuar por la propia perspectiva de acción y no por los lineamientos previamente establecidos, como es la estructura orgánica. ${ }^{4}$

concepto comportamiento administrativo y no el término administración porque sostenemos que toda actividad administrativa es intencionada, realizada por sujetos, los cuales definen un tipo de comportamiento; la acción administrativa que se proyecta en el comportamiento administrativo no es la llana realización de un procedimiento, sino que responde a la forma en que se ejecuta, mediado por la división del trabajo y por un sistema de objetivos organizacionales.

${ }^{2}$ Entenderemos por legitimidad de la autoridad el reconocimiento racional, informado y voluntario de los miembros en la aceptación de un mandato. Los individuos son quienes legitiman las directrices de acción que se realizan en la organización, y ofrecen la posibilidad de validar colectivamente el actuar de la autoridad, lo que permite que sus mandatos sean reconocidos permanentemente por los subordinados, independientemente de la justificación formal que le otorga la estructura orgánica. Gracias al acuerdo implícito que se establece entre los sujetos en la realización de la función, la legitimidad se desprende de la vertiente normativa y se erige como una posibilidad de validación de las acciones de la autoridad. Es así como la legitimación de la autoridad en el comportamiento administrativo se fundamenta en el actuar cotidiano, bien sea mediante el desarrollo de las tareas, por las aptitudes para el cumplimiento de las funciones, o algunas otras cualidades de los actores que orienten el trabajo colectivo, como el don de mando, el respeto y la experiencia, entre otras. Quienes obedecen en un ámbito de legitimidad lo hacen por la vigencia efectiva de los mandatos y del sentido de la acción misma, y los individuos la asumen como máxima de obrar en su espacio de actuación; en tanto que la autoridad —aquella persona que tiene la capacidad de establecer las directrices de acción - posee el consentimiento de todos los actores para asumir ese rol, de manera que sus órdenes están enmarcadas dentro de un ámbito particular de validez reconocidas de manera informada y voluntaria por quienes participan en esa relación social. La relevancia de la legitimidad en la organización estriba en el consentimiento de los sujetos para aceptar libremente sus tareas y dotar a la autoridad de su reconocimiento para dirigirlas.

${ }^{3}$ Con el fin de evitar la confusión en los conceptos de poder y autoridad, utilizaremos la palabra dominación para hacer referencia a la disposición que tienen ciertos sujetos sobre la voluntad de otros para la realización de ciertas acciones, según podemos derivarlo del concepto de dominación de Max Weber (1999: 43), quien define el término dominación como "la probabilidad de encontrar obediencia a un mandato de determinado contenido entre personas dadas". Si bien el concepto de dominación puede interpretarse como coacción o manipulación de la voluntad, también puede comprenderse, según la definición weberiana, como la posibilidad de que los mandatos sean acatados por voluntad propia de manera consciente (Weber, 1999: 170) en donde su principal sustento es la creencia de los subordinados en la legitimidad de su subordinación (Giddens, 1998: 259). En suma, tomamos el término dominación para referirnos más genéricamente a la relación entre dominantes y dominados.

${ }^{4}$ Entenderemos por estructura orgánica un orden funcional dispuesto formalmente en una organización; la estructura orgánica responde a relaciones funcionales, precisión de tareas individuales y colectivas, así como a la delimitación de responsabilidades que es preciso fijar mediante reglas y ordenanzas (Vid., Mayntz, 1974: 155). 
El control social en las organizaciones es propio del poder $^{5}$ y de la autoridad; ${ }^{6}$ si bien el poder y la autoridad aluden a cuestiones de dominación, lo que las distinguen es la forma en que se concibe la relación de mando y obediencia, bien sea que los dominados asuman un ordenamiento como parte implícita de su condición de subordinados, en el que un dirigente apele al elemento coercitivo como posible instancia de validez para obligar al cumplimiento de los mandatos, o bien que el carácter dominante se encuentre provisto del acuerdo consensual entre los actores que tienda al reconocimiento intersubjetivo entre los actores frente a los actos de autoridad. En el primer caso nos referimos al significado del poder, en tanto que el segundo define el concepto de autoridad; es decir, la coercitividad define al poder y la legitimidad, a la autoridad. El concepto de autoridad está determinado por los procesos de legitimación que se producen en una relación de mando y obediencia dentro de las organizaciones $;^{7}$ en este trabajo sostenemos que la autoridad no se

\footnotetext{
${ }^{5}$ En este artículo entenderemos por poder como la capacidad coactiva que tienen ciertos sujetos para ejercer el dominio de los actores que participan en un sistema de acción. La fuente de explicación del concepto de poder en el comportamiento administrativo es la estructura orgánica, la cual brinda los elementos suficientes de dominio para ejercer dicha dominación, incluso su carácter coactivo como última instancia de validez. Si bien el concepto de poder se puede aplicar a toda relación de domino, como un atributo de ciertos individuos para alcanzar determinados propósitos, en este trabajo sostenemos que el poder aspira a la coacción, lo cual constituye su cualidad fundamental; en este sentido, el carácter coactivo del poder materializa la dominación. Buckley define al poder, desde esta vertiente, como el control o influencia de ciertos actores sobre las acciones de otros para promover sus metas sin el consentimiento de éstos, contra su "voluntad", o sin su consentimiento o comprensión; los mecanismos que caracterizan al poder van desde la fuerza física hasta la adjudicación de recompensas adicionales, pasando por la manipulación de símbolos, información y de otras condiciones ambientales (Buckley, 1993: 271). El poder es una condición atribuible al propio sujeto que lo ejerce, sin atender necesariamente al acuerdo consensual de los miembros que conforman una relación social.

${ }^{6}$ Entenderemos por autoridad como "el control de la conducta de otros para la promoción de metas colectivas, basada en alguna forma discernible de consentimiento cognoscible de éstos. La autoridad implica una sujeción informada y voluntaria, que es un estado psicológico definido, y una coordinación o identidad de las orientaciones hacia metas de los controladores y controlados." (Buckley, 1993: 271). En el concepto de autoridad, los miembros asumen la condición de subordinación de una manera informada, es decir, con el reconocimiento pleno de que alguien más cuenta con mejores posibilidades de acción para orientar la función. Gracias a esta conformidad cognoscible de los participantes es posible hacer referencia a la justificación de la forma de conducta de la autoridad. En este concepto de autoridad se comprende que los miembros de la organización asumen que la directriz de los mandatos tiene el referente objetivo de una dominación informada y voluntaria, con lo que es posible apelar al acuerdo consensual para validar el comportamiento colectivo que sugiere la autoridad para el cumplimiento de las funciones.

${ }^{7}$ Entenderemos por organización como "una colectividad con una frontera relativamente identificable, un orden normativo, niveles de autoridad, sistemas de comunicaciones y sistemas de coordinación de membresías; esta colectividad existe de manera continua en un ambiente y se involucra en actividades que se relacionan por lo general con un conjunto de metas; las actividades tienen resultados para los miembros de la organización, la organización misma y la sociedad" (Hall, 1996: 33).
} 
genera a partir de los preceptos normativos que conforman la estructura orgánica, sino que es una derivación de la legitimidad, cuyo ámbito de significado se sustenta a partir del acuerdo consensual de los dominados, quienes asumen voluntariamente su condición por estar provista de mecanismos de participación racional que tienden al reconocimiento y validez de los actos de autoridad.

\section{El concepto de autoridad en el pensamiento de Aristóteles}

El concepto de ciudad (p ól i V) en los pensamientos platónico y aristotélico es imprescindible para comprender las distintas formas de participación comunitarias. El rasgo característico de las relaciones sociales es la acción individual o colectiva, que en última instancia se realiza en beneficio de la comunidad política. Para Aristóteles, toda acción se sustenta en un bien, y el bien supremo entre todos ellos es aquel que está orientado al bien de la ciudad. Las referencias conceptuales que encontramos en Aristóteles con respecto a la autoridad están enmarcadas fundamentalmente en la concepción de los gobernantes. La dominación que ejerce el padre sobre el hijo o el marido sobre la esposa difiere en amplio sentido con el del gobernante sobre el gobernado, o del amo sobre el esclavo. Sin embargo, estos niveles de mando tienen una referencia común: la procuración del bien de los demás. El beneficio común hace que se gobierne para el bien de todos, debido a que el beneficio de unos es el beneficio de los demás. En Aristóteles, la autoridad funge como el elemento indispensable para dirigir mejor los destinos de los ciudadanos, en beneficio de la comunidad; y de exigir, al mismo tiempo, el mejor ejercicio de las funciones de los demás, las cuales se inscriben dentro del ámbito de coordinación de las actividades que realiza la autoridad, de manera que siempre existe una relación directa entre el trabajo y la virtud.

El sustento de la autoridad en Aristóteles es la comunidad. Esta categoría de análisis no sólo responde al control social para alcanzar los objetivos comunitarios, sino que obedece a un ámbito de responsabilidad compartida entre quienes ejercen el dominio y los dominados, lo que significa asumir el carácter legítimo de la autoridad por estar sustentado en un propósito común, que conlleva la asunción de mandatos como orientaciones de la conducta plenamente reconocidas por todos. Los mecanismos de participación de los sujetos investidos de mando obedecen al carácter previamente legitimado de sus acciones, en el sentido de responder a una condición social que le da un sustento moral a sus directrices de acción, con lo que el actuar concreto de la autoridad se justifica en la capacidad individual para ejercer las tareas de mando. 
Pues no pueden ser hermosas las acciones de quien no se distingue tanto como el varón de la mujer o el padre de los hijos o el amo de los esclavos, de modo que el que se ha apartado del buen camino no puede rectificar luego en la medida que se ha desviado de la virtud. ${ }^{8}$ Pues entre iguales, lo bueno y lo justo consiste en una alternancia, y esto es lo igual y lo semejante. En cambio, lo desigual para los desiguales y lo no semejante para los semejantes es contrario a la naturaleza, y nada contrario a la naturaleza es hermoso. Por eso, siempre que alguien que sea superior en virtud y en capacidad para realizar las mejores acciones, a ése es noble seguirle y justo obedecerle. Pero debe poseer no sólo virtud, sino capacidad que le haga apto para la acción (Aristóteles, 2000b: 1325b). ${ }^{9}$

La naturaleza de la virtud en los hombres consiste en la realización de las mejores acciones de acuerdo con la capacidad para servir mejor a la comunidad, lo que proyecta procesos de legitimación de la autoridad. Si bien Aristóteles distingue a la virtud de la capacidad, sostenemos que ambas concepciones son parte de una misma comprensión de las acciones del hombre, debido a que un hombre virtuoso es capaz de realizar las mejores funciones porque posee las cualidades particulares que lo hacen más apto para emprender de la mejor manera las obras que le son propias. La virtud de la autoridad se refiere a las acciones individuales referidas a la comunidad y a la valoración de los hombres para cumplir con las tareas que no le son ajenas, con lo que podemos identificar la legitimidad de la autoridad en el pensamiento de Aristóteles, lo cual representa una orientación conceptual para explicar el concepto de autoridad en el comportamiento administrativo.

Esta noción de la autoridad también la encontramos en Hans-Georg Gadamer, orientada en el mismo sentido de la concepción aristotélica, referida a la capacidad de que disponen ciertos hombres para dirigir la función, misma que se sustenta en la virtud y en los actos virtuosos:

Autoridad no es la superioridad de un poder que reclama obediencia ciega y prohíbe pensar. La verdadera esencia de la autoridad reside en no poder ser irracional, en ser un imperativo de la razón, en presuponer en el otro un conocimiento superior que rebasa el juicio propio. Obedecer a la autoridad significa entender que

\footnotetext{
${ }^{8}$ El concepto de virtud al que hacemos referencia en Aristóteles es el siguiente: "Se ha de notar, pues, que toda virtud lleva a término la buena disposición de aquello de lo cual es virtud y hace que realice bien su función; por ejemplo, la virtud del ojo hace bueno al ojo y su función (pues vemos bien por la virtud del ojo) [...]. Si esto es así en todos los casos, la virtud del hombre será también el modo de ser por el cual el hombre se hace bueno y por el cual realiza bien su función propia" (Aristóteles, 2000a: 1106a).

${ }^{9}$ El subrayado es nuestro.
} 
el otro - también la voz que resuena desde la tradición y la autoridad — puede percibir algo mejor que uno mismo (Gadamer, 2000: 45). ${ }^{10}$

El imperativo de la autoridad en cualquier ámbito de responsabilidad es apelar a la razón, cuyo significado es conformar su legitimación ante los demás para un mejor ejercicio de la función, una connotación que ya advertían Henri Fayol y Mary Parker Follett en sus conceptos de autoridad personal (Vid., Cruz, 2004: 6 y ss.). Gadamer señala que la autoridad es un atributo de personas, que no tiene su último fundamento en un acto de sumisión y abdicación de la razón, sino que en un acto de reconocimiento y conocimiento: se reconoce que el otro (la autoridad) está por encima de uno en juicio y perspectiva, por lo que, en consecuencia, su juicio es preferente y tiene primacía respecto al propio. Gadamer (2000: 347) concluye que la autoridad no se otorga sino que se adquiere, y tiene que ser adquirida si se quiere apelar a ella. La autoridad queda plenamente validada cuando existe el carácter objetivo de su reconocimiento frente a los demás, bien sea por la capacidad de discernir racionalmente el curso de las acciones, por la aptitud para la realización de las tareas, o bien porque se encuentra inscrita dentro de las actividades virtuosas que son propias en cada uno de los sujetos que ejercen el dominio. El hecho de que la autoridad no se otorga - como sucede en el nombramiento formal de cualquier organización cuando se trata de apelar a un régimen administrativo-, sino que se adquiere conforme a los escenarios de legitimación, en el sentido de que la dominación sea reconocida voluntaria, informada y racionalmente por quienes forman parte de la relación social de mando y obediencia.

El concepto aristotélico de autoridad se encuentra suscrito a la legitimidad, que se deriva de la razón moral que acompaña a la condición humana de la comunidad y del significado que encarna la concepción de la virtud, en la cual se asume el conocimiento de la función como la esencia en la orientación de las acciones. El reconocimiento implícito que se atribuía a los individuos que eran susceptibles de ejercer la dominación representaba una consecuencia de la igualdad que privaba entre los que se consideraban ciudadanos; es decir, aquellos que contaban con el derecho de participar en los asuntos de la ciudad, de modo que la validez de comportamiento en torno a los actos de autoridad constituía un elemento implícito de conducta para emprender las tareas propias de su función comunitaria, que respondieran íntegramente a los más altos valores de la comunidad. En Aristóteles la autoridad fungía como parte de un andamiaje funcional que respondía a un ob-

\footnotetext{
${ }^{10}$ El subrayado es nuestro.
} 
jetivo comunitario para el cuidado de los asuntos domésticos, que repercutía en el mayor bien para quienes conformaban una familia, o para procurar el mayor bien para los ciudadanos, como sucedía con los gobernantes; esta connotación no era diferente entre las diversas formas que adquiría la autoridad en la familia, la tribu o en la ciudad, debido a que prevaleció la idea del bien común, lo que significaba un bien a la autoridad misma porque obedecía a una concepción moral inseparable de la vida humana, y, en este sentido, el bien de los demás correspondía con el bien propio, por eso es que la alternancia de los ciudadanos para dirigir los asuntos de la ciudad podían ser asumidos por cualquier ciudadano, pues los principios morales para conformar la comunidad debían prevalecer sobre cualquier otro interés colectivo o particular; asimismo, cualquier ciudadano era digno de asumir las funciones gubernamentales porque su condición de igualdad le permitía enmarcar su comportamiento dentro del ámbito de la virtud porque era una cualidad inseparable de todo ciudadano, lo que le proveía de los elementos de acción para emprender las más nobles tareas.

La doble dimensión que existía en los gobernantes en el pensamiento de Aristóteles, en cuanto a la idea de virtud y la asunción de los gobernantes, garantizaba que las acciones de gobierno sirvieran a los intereses comunitarios porque respondían a una formación común como ciudadanos. El gobierno por turno procuraba materializar la igualdad entre los ciudadanos, como una forma democrática de asumir los asuntos públicos de la polis. Es por ello que lo que nos interesa resaltar en este trabajo es la idea del gobierno por turno, por el carácter participativo de quienes son susceptibles de dirigir, cuando están inmersos dentro de la concepción de la obediencia, debido a que esto último generaba en los sujetos la asunción de responsabilidades y el aprendizaje en la realización de las tareas, como parte fundamental de su preparación para ejercer funciones de mando. En este sentido, la autoridad no sólo fungía como portadora de una dominación, sino que permitía establecer directrices legítimas de comportamiento colectivo, debido a que los mecanismos de coordinación que proyectaba la autoridad se encontraban sustentados en el conocimiento de la función. Asimismo, la connotación aristotélica del gobierno por turno además de que respondía a la participación común, al aprendizaje de las tareas y a la adquisición de responsabilidades, conformaba la oportunidad de servir a la ciudad de la mejor manera posible porque respondía a los actos virtuosos de cada quien.

La relación de dominio que contiene el concepto de autoridad en Aristóteles proyecta el derecho de mando, y para este pensador el mando define al poder: "Pero 
el título de magistrado, hablando en términos absolutos, debe aplicarse sobre todo a los cargos a los cuales se encomienda deliberar sobre ciertos asuntos, el juzgar y el mandar, y sobre todo esto último, pues el mandar es por excelencia lo propio del poder" (Aristóteles, 2000b: 1299a). Los elementos de análisis que subyacen a la explicación del poder estriban en el derecho de ciertos individuos para ejercer el mando, para dirigir determinadas funciones y en la capacidad para la realización de las tareas, que también podríamos denominarla como competencia para asumir las responsabilidades propias de un área de acción. Gracias a la concepción del poder que contiene el pensamiento aristotélico pueden consumarse las más nobles obras, con lo que podemos decir que su sustento es enteramente ético, cuando señala que "las acciones de los hombres justos y prudentes - cuyas cualidades son propias de quienes ejercen el dominio- son el fin de muchas obras nobles", para consumar "las mayores y más ilustres acciones" (Aristóteles, 2000b: 1325a), es decir, no se trataba de ejercer el poder por el poder mismo, sino que su aspiración era el resultado de una conducta moral que respondía al interés común, al beneficio comunitario.

Para Aristóteles las directrices del poder que orientan el comportamiento de los sujetos estriban en identificar una finalidad moral, que es lo que define la esencia de la autoridad, y lo que constituye su principio de legitimación. En este mismo sentido, Luis Villoro atribuye al concepto de poder esta cualidad cuando está justificado positivamente en un fin valioso que permite la realización de las mejores obras:

Deseamos el poder para obtener, gracias a él, otra cosa. Es pues un valor 'extrínseco', es decir, vale en la medida en que contribuya a la realización de un fin valioso por sí mismo. Si el fin tiene un valor intrínseco, el poder es igualmente valioso. Podemos pensar en una sociedad donde el poder tuviera ese sentido positivo. Sería entonces el medio para lograr un bien común y el término de una voluntad general. Los miembros de una sociedad semejante coordinan sus fuerzas en la caza, suman sus esfuerzos en el momento de la cosecha, conciertan sus habilidades en el trabajo colectivo" (Villoro, 2001: 81). ${ }^{11}$

Si el sentido de la dominación es éste, entonces el poder se finca a partir de la obtención de una finalidad moral, que para Aristóteles consiste en alcanzar un be-

${ }^{11}$ El subrayado es nuestro. 
neficio comunitario, es decir, a partir del sentido positivo al que alude Villoro en su explicación, en el que se atribuye su carácter valorativo. ${ }^{12}$

El beneficio común es lo que define inicialmente el concepto de autoridad en Aristóteles, y lo que justifica el ejercicio del poder por parte de la persona investida de mando para dirigir sus acciones, de ahí la relevancia que adquiere el significado del poder, que no representa, en esta tesitura, un elemento que sea comparable conceptualmente con la autoridad, sino que se erige en función de ésta; esto es, el poder como medio de realización de las tareas propias de la autoridad, con lo que se asume una distinción conceptual con respecto al concepto de poder en el comportamiento administrativo que hemos definido en este trabajo. En este sentido, el concepto de autoridad de Aristóteles es más amplio que el de poder, porque éste es una cualidad de aquél; el elemento del que dispone la autoridad para emprender su finalidad legítima obedece a las posibilidades del poder, como mecanismo de acción para la realización de las mejores obras o las más nobles tareas.

En el comportamiento administrativo se requiere de una autoridad que dirija y coordine el esfuerzo común, en aras de lograr determinados objetivos, y una autoridad legítima está encarnada en el hombre más apto para la coordinación o realización de las tareas, que en términos aristotélicos sería aquella que tenga la virtud más probada para cumplirlas de la mejor manera. Para Aristóteles, el poder que tiene la autoridad para ejecutar o dirigir las actividades está en función de la realización de las mejores obras, y la autoridad legítima en el comportamiento administrativo sirve para alcanzar de la mejor manera los objetivos organizacionales; la diferencia entre ambas concepciones es el espacio de acción, pues mientras que para el pensamiento aristotélico es el bien común, en la organización es el cumplimiento de los objetivos que ella misma señala, aunque bien sabemos que esto está condicionado para otorgar, en última instancia, un beneficio social, mismo que es el resultado de la división del trabajo, en la que cada organización genera los satisfactores que requiere la comunidad para su subsistencia.

\footnotetext{
${ }^{12}$ Luis Villoro (2001: 13) señala que una determinante del valor de un objeto o de una situación se inscribe dentro de una vertiente positiva o favorable de significado, y cuando se tiene una actitud favorable hacia una clase de objetos, se consideran valiosos, porque se cree que tiene ciertas propiedades y éstas causan agrado; por ejemplo, la acción de un amigo se considera valiosa si se cree revestida de ciertos rasgos que, a la vez, se aprecian, o bien para conceder valor a una sociedad democrática, se tiene que creer en ciertas características de esa forma de gobierno y, al mismo tiempo, estimarlas. Creer en algo es tenerlo como componente del mundo real y estar dispuesto a actuar en consecuencia.
} 
El poder de ese jefe no está separado del poder del grupo, es uno de sus elementos. Ejerce autoridad sobre los demás en la medida en que sirve para realizar un bien común. La voluntad de la autoridad no se impone a las voluntades ajenas. Su función es hacer eficaz el poder de todos, al unificarlos en una acción colectiva. Ésta sería una sociedad en la que, en sentido estricto, nadie impone su voluntad; en ella no existe, por lo tanto un poder político (Villoro, 2001: 81). ${ }^{13}$

La concepción del poder que señala Villoro funge como el elemento de articulación entre los actos de la autoridad con la consecución de las metas comunes, pero se trata de emprender los objetivos propios de una colectividad, en donde no se establece como última instancia de validez el elemento coactivo, sino el carácter legítimo para la realización de las obras colectivas que les son propias, una explicación muy cercana a la idea de poder que indica Mary Parker Follett (1995: 97-119 y 141-154). La legitimidad de la autoridad se manifiesta en la obtención de un fin comunitario, como podemos deducirlo de la teoría aristotélica, y en la capacidad para coordinar los esfuerzos colectivos, como lo entendemos en el comportamiento administrativo. El poder, en este sentido, ya no sólo responde al carácter impositivo de los mandatos sino que apela, contrariamente, a la legitimidad, al poder legítimo que ejerce la autoridad para alcanzar ciertos fines, en el contexto de un reconocimiento común, informado y voluntario, de los subordinados, validados por el acuerdo implícito entre ellos y la autoridad, y que en todo momento está supeditado al carácter racional de las acciones.

El concepto de autoridad que señala Aristóteles proyecta ese poder legítimo que se inserta dentro de un ámbito de validez común, entre quienes ejercen la dominación y los dominados. Los mecanismos de participación colectivos responden a la capacidad de los dirigentes para orientar de la mejor manera las funciones en el contexto de un acuerdo intersubjetivo, en el que prevalece el reconocimiento de los actores por aceptar voluntariamente el poder de la autoridad como medio legítimo para regir las tareas. Las posibilidades de acción quedan enmarcadas en la relación existente entre la autoridad y los demás individuos como medio de orientación reconocido por todos los participantes. La validez de las acciones se establece en la propia capacidad de los dirigentes para ejercer la función, y esto constituye el elemento de inicio en el que se funda la legitimidad de la autoridad en el pensamiento aristotélico, junto con la adecuación de sus acciones al régimen establecido y las

${ }^{13}$ El subrayado es nuestro y las cursivas están en el original. 
perspectivas de actuación virtuosa y justa. Estas fuentes de legitimidad que señala Aristóteles están contenidas en el significado de las magistraturas, que es lo más cercano al concepto de la autoridad que intentamos explorar.

Para Aristóteles (2000c: 1309a) "Tres condiciones deben tener los que van a desempeñar las magistraturas supremas: en primer lugar, amor al régimen establecido; en segundo lugar la mayor competencia en las tareas de su cargo, y en tercer lugar, una virtud y una justicia en cada régimen adecuadas a ese régimen, pues si lo justo no es lo mismo en todos los regímenes, necesariamente habrá también diferentes clases de justicia”. Estas cualidades señaladas por Aristóteles condicionan el comportamiento de los dirigentes para emprender las acciones propias de su función. En primer término, si bien "el amor al régimen establecido" no tiene un referente claro de interpretación, podemos comprenderlo como la firme creencia de los actores en las directrices propias que se instituyen en un régimen, que para el pensamiento de Aristóteles tendrían que estar referidas a la comunidad; el convencimiento en la consecución de objetivos que plantea un sistema de actuación social es el referente de inicio para que los individuos emprendan las tareas propias de su función, principalmente para dar paso a sus acciones virtuosas. El amor al régimen establecido en el pensamiento de Aristóteles tiene que leerse como el amor a la comunidad, a la conformación organizada de los individuos dentro de la ciudad, la cual representa el contexto de significado bajo el que es posible pensar en un comportamiento comprometido con lo que es común. El referente más inmediato que podemos encontrar en torno a las organizaciones, desde esta perspectiva, es el carácter ético de los sujetos investidos de mando, en el sentido de que su acción se condiciona a la consecución de los objetivos organizacionales: "La aportación individual más importante que se exige del elemento dirigente, y, por cierto, de calidad más universal, es la lealtad, la dominación por la personalidad de la organización" Barnard, 1975: 19). La creencia en lo que promueve la organización significa, al mismo tiempo, asumir un compromiso con ésta que en última instancia redundará en un bien común, para satisfacer las necesidades sociales.

Queda claro que en el pensamiento aristotélico el "amor al régimen establecido" se plantea como una clara referencia a la comunidad para el bienestar común. En tanto la lealtad de la autoridad a la organización, que la hemos tomado como el símil del principio aristotélico del "amor al régimen establecido", puede interpretarse en dos sentidos: por la simple creencia en los objetivos que persigue una organización, por ejemplo, en una universidad —el amor a la educación, a la investigación o a la difusión de la cultura—, un hospital o una institución de beneficencia —el amor 
por ayudar al prójimo; y como una necesidad particular de los hombres por asumir una responsabilidad social dentro del sistema de actuación al que pertenece.

El "amor al régimen establecido" contextualiza el significado de comportamiento de los actores dentro de un sistema, que posteriormente se materializa en la propia función, que es, precisamente la aptitud para ejercer la autoridad, que es la segunda característica que señala Aristóteles, la cual consiste en la capacidad de los individuos para emprender las tareas propias de su cargo; para Aristóteles esto no significa únicamente el hecho de tener pericia para la realización de las actividades, sino una labor comprometida con la comunidad, es decir, la autoridad se convierte en un ente responsable de acción frente a los demás, y gracias a ello adquiere mayor relevancia su capacidad para la realización de los actos. En el comportamiento administrativo esta cualidad brinda las posibilidades de legitimar a la autoridad frente a los demás, debido a que permite que se reconozca en la organización a la persona idónea para dirigir las funciones, tanto por su habilidad como por su conocimiento, lo cual está estrechamente relacionado con la tercera particularidad que señala Aristóteles que son la virtud y la justicia. El significado de la virtud comprende la capacidad de realizar las acciones que son propias de los individuos, orientadas al beneficio comunitario y a su realización espiritual, en la forma de la consecución de una obra individual. En el ámbito de la autoridad en el comportamiento administrativo, la virtud comprende las cualidades vocacionales que posee el individuo para dirigir la función en tanto la justicia funge como la racionalización de los actos de autoridad de manera equitativa entre todos quienes conforman un sistema de interactuación.

La autoridad en el pensamiento de Aristóteles tiene una referencia explícita hacia los demás, como ya lo hemos advertido, de modo que mientras el funcionamiento de una comunidad esté enmarcado en la eficacia será en beneficio de ella misma y del propio individuo que ejerce el mando. En este contexto, la autoridad cumplirá mejor su responsabilidad y adquirirá mayor validez en sus funciones si es capaz de alcanzar la coordinación adecuada de todos los miembros, porque el bien de los demás también será el bien personal. El ejercicio de la autoridad estará mejor reconocido si recibe de los subordinados su aceptación, de manera que adquiere la mayor legitimidad para ejercer de la mejor manera la dominación. 


\section{El concepto de autoridad en el comportamiento administrativo}

El concepto de autoridad en Aristóteles que hemos expuesto se define fundamentalmente por la legitimidad. Los elementos de análisis que explican, por el momento, la legitimidad de la autoridad en el pensamiento de Aristóteles son el bien común, esto es, la perspectiva de acción que se sustenta a partir de la realización de un bien, así como el conocimiento de la función que acompaña a la capacidad para la realización de la acción, lo que es una derivación de la virtud, en el sentido de emprender una actividad auténtica al ser. Estas dos dimensiones de la legitimidad de la autoridad en Aristóteles definen la legitimidad de la autoridad en el comportamiento administrativo; en primer término, porque toda vertiente de acción que se desarrolla en las organizaciones se justifica a partir de la realización de un objetivo, mismo que responde a una necesidad social, de modo que las funciones particulares sirven a un propósito más amplio de significado que es la comunidad. En segundo término, porque lo que explica la administración es la acción funcional de los sujetos, los cuales obedecen a las capacidades individuales, que es lo que legitima, en mayor medida, los actos de autoridad. Esta última vertiente es la que se explorará en este apartado, de modo que permita vincular el concepto de autoridad de Aristóteles, que se ha analizado, con el concepto de autoridad en el comportamiento administrativo. Se trata de definir, por ahora, el carácter legítimo de la autoridad a partir de la propia función con la finalidad de comprender el concepto de autoridad en el comportamiento administrativo.

Tanto el poder como la autoridad son relaciones de dominio; ${ }^{14}$ la diferencia estriba en que el poder, como lo entendemos en este trabajo, apela a los elementos coactivos de control como última instancia de validez para orientar las acciones de los actores o para aspirar a su obediencia, sustentados fundamentalmente en los lineamientos establecidos por el sistema normativo, en tanto que la autoridad es una relación de reconocimiento y validez intersubjetiva que aspira al consenso colectivo para alcanzar la legitimidad en los hechos, mediante la realización de la propia función, cuando hablamos concretamente del comportamiento administrativo.

\footnotetext{
${ }^{14}$ Cuando aludimos al concepto de dominación a partir de la perspectiva propia de la autoridad, podemos ubicarlo en el plano de estudio que señala Max Weber (1999: 699): “[...] entendemos aquí por 'dominación’ un estado de cosas por el cual una voluntad manifiesta ('mandato') del 'dominador' o de los 'dominadores' influye sobre los actos de los otros (del 'dominado' o de los 'dominados'), de tal suerte que en un grado socialmente relevante estos actos tienen lugar como si los dominados hubieran adoptado por sí mismos y como máxima de su obrar el contenido del mandato ('obediencia').
} 
La dominación que surge del poder en el comportamiento administrativo puede materializarse por dos vías: previamente a la relación efectiva de mando y obediencia, es decir, aquella que se otorga mediante los mecanismos legales previstos por la estructura orgánica; y a través del vínculo fáctico que se produce en el propio actuar de los sujetos, esto es, posterior al nombramiento y en la relación funcional que se desarrolla en las actividades cotidianas de los actores. La dominación legítima, la que origina el concepto de autoridad que sugerimos para este trabajo, únicamente puede concretarse en la realización de la función, por su virtud, en el proceso de interacción de los individuos que reconocen en ciertos actores la capacidad para dirigir las tareas. Michel Crozier y Erhard Friedberg reconocen cuatro fuentes de poder para una organización: aquellas que provienen del control de una competencia particular y de la especialización funcional; las que están ligadas a las relaciones entre una organización y sus entornos; las que nacen del control de la comunicación y de la información, y las que provienen de la existencia de las reglas organizativas generales (Crozier y Friedberg, 1990: 69). Consideramos que el poder que se deriva de las relaciones de la organización y sus entornos, del control de las comunicaciones y de la información, así como las que se generan por la existencia de reglas organizativas, no responden a la categoría conceptual de la autoridad que propondremos en la legitimación del comportamiento administrativo por los siguientes motivos. En el primer caso, porque lo que nos interesa estudiar son los vínculos que se establecen al interior de la organización, como procesos de interrelación funcional entre quien detenta la dominación y los subordinados; en el segundo caso, porque la dominación que nace de las comunicaciones y de la información tiene un determinante previo de poder que sustenta su actuación, ya sea por la propia estructura orgánica o bien por una condición estipulada por las líneas de mando que otorgan cierta predominancia de unos actores sobre otros, independientemente de las relaciones propias de la función; y finalmente, en el tercer caso, porque la estructura formal es una de las partes fundamentales del concepto de poder, en el sentido de que la validez de los actos de los dirigentes está supeditado al control coercitivo legalizado como posibilidad de acción para obligar a los actores a acatar una orden, es decir, el carácter coactivo que se deriva del aparato normativo define al poder como última instancia de validez de los ordenamientos; esta dimensión no otorga mayor legitimidad que la propia legalidad. Estas tres condiciones conforman parte de la esencia del concepto de poder que nos sirve para distinguirlo del concepto de autoridad que proponemos.

Al margen de la denominación que le otorgan Crozier y Friedberg a las relaciones de dominación como relaciones de poder, el concepto de autoridad alude parcial- 
mente al control de una competencia particular y de la especialización funcional, debido a que obedece, en mayor medida, al reconocimiento intersubjetivo de los actores por aceptar en los sujetos la capacidad para orientar las actividades que otorga procesos de legitimación a los actos de autoridad; decimos que esta vertiente define parcialmente el concepto de autoridad porque también existen otras fuentes de legitimación de la autoridad en la administración como son el don de mando, el carisma, la personalidad o la experiencia. Sin embargo, consideramos de suma relevancia establecer como la principal fuente de legitimidad de la autoridad en el comportamiento administrativo la competencia individual que aspira a la especialización, debido a que constituye una manifestación objetiva de las acciones concretas que se desarrollan en las organizaciones, como quedó definido en uno de sus aspectos con el análisis del concepto de autoridad en el pensamiento de Aristóteles. La competencia particular y la especialización funcional en el comportamiento administrativo se vinculan con el pensamiento de Aristóteles en el sentido de que toda actividad inmersa en la legitimidad se define por la virtud, como la posibilidad de los actores de realizar una función que les es propia, por eso es que consideramos en este trabajo como la más importante fuente de legitimidad de la autoridad en la administración.

Si la dominación se encuentra inserta dentro de la vertiente propia del poder entonces los elementos coactivos de dominio prevalecen como elementos de obligatoriedad hacia los actores para acreditar el comportamiento colectivo; en tanto si la dominación resulta de un proceso de justificación racional y voluntario por parte de los subordinados, enmarcado en un acuerdo consensual, entonces se entiende como autoridad. En este sentido, la autoridad otorgada por consenso no puede interpretarse al mismo tiempo como el poder que confiere autoridad, debido a que esto equivale a señalar que la mayoría consiente que se la aplique la coerción (Buckley, 1993: 262-263). Cuando los esquemas de participación colectivos tienden a asumir el poder como posibilidad coercitiva de dominio entonces la legitimación de los actos de autoridad ya no puede conformar el acuerdo consensuado de los subordinados, en razón de que el poder lo ha suplantado, la fuerza adquiere mayor relevancia que el acuerdo para el sostenimiento del orden establecido (Buckley, 1993: 262-263), por lo que ya no es posible comprender el significado de una autoridad legítima. Mientras prevalezca el poder en la relación de mando y obediencia, la legitimidad no tiene razón de ser, y el concepto de autoridad pierde su sustento, pues su esencia es, precisamente, la legitimación, la creencia racional de que la disposición de mandatos constituye la más pertinente para la realización de la función. 
Con la legitimidad, la autoridad no sólo encarna la justificación del dominio, sino que proyecta mecanismos de articulación de todos los actores, dentro de un ámbito de reconocimiento intersubjetivo y al margen del carácter impositivo que genera el poder; en sí misma, la figura de la autoridad conjunta el esfuerzo colectivo mediante la coordinación de todos sus componentes; sin embargo, lo que genera la legitimación de la autoridad en el comportamiento administrativo es la validez a los procesos decisorios. Para Talcott Parsons, la autoridad es el derecho legítimo a adoptar ciertas decisiones y a obligar con ellas a la colectividad (Parsons, 1997: 120). Aunque la explicación que señala Parsons sobre la autoridad se encuentran más cercanas a la estipulación de la estructura jerárquica y, por lo tanto, se ubica en el ámbito del poder político, consideramos que en las organizaciones cuando la autoridad se legitima asume el control decisorio sobre los elementos disponibles para alcanzar la coordinación de los individuos que confluyen en el actuar colectivo, provisto de una serie de factores que le otorgan el derecho de primacía en la regulación de las funciones, con vistas a lograr ciertos objetivos. En este sentido, la obligatoriedad de los agentes por cumplir con las tareas encomendadas por la autoridad no es un hecho que se genere a partir del nombramiento administrativo, sino que es la consecuencia del acuerdo consensuado de los individuos por reconocer en ella las mejores directrices para orientar la acción colectiva.

Cuando los actores disponen de los medios legítimos de dominio en el comportamiento administrativo la obediencia es una consecuencia del reconocimiento implícito de los sujetos por admitir que quien dirige la función es la persona idónea para el desarrollo de la misma, incluso si no cuenta con la designación expresa que señala la estructura jerárquica. Sin atribuir al especialista de una tarea la condición enajenante del trabajo, como sucede frecuentemente en la mecanización de las acciones que se realizan en la industria capitalista y que se ha teorizado en la llamada escuela de la administración científica, una persona de alta competencia técnica se convierte en la autoridad de la función específica que desarrolla, misma que no puede ser juzgada en sus decisiones y en su cualidad técnica por un superior jerárquico en la organización, a menos de que esa misma autoridad jerárquica cuente con una preparación profesional similar o los conocimientos suficientes del cargo para emitir un juicio acerca de su trabajo. En este sentido, es preciso que se reconozca al especialista, dentro de esa esfera técnica, y cuente con una relativa libertad respecto a la intervención de la autoridad formal (Parsons, 1997: 127). Lo que prevalece en la legitimidad de la autoridad por la función es el conocimiento concreto y no el carácter lineal de las decisiones que proyecta la estructura orgánica. Se trata de la autoridad otorgada por la función que los demás miembros 
reconocen como legítima, de manera que la posibilidad de mando se fundamenta en esa objetiva condición valorativa.

La influencia que se genera por los conocimientos técnicos de estos actores adquiere una relevancia determinante para asumir una parte de la dominación, que media dentro de un ámbito de negociación específico:

De tal suerte, estudiar una organización desde el punto de vista de las relaciones de poder a través de las cuales los actores organizativos manipulan las zonas de incertidumbre con que cuentan para negociar continuamente su propia voluntad y para imponer, en la medida de lo posible, sus propias orientaciones a otros actores, nos revela una segunda estructura de poder, paralela a la que el organigrama oficial codifica y legitima (Crozier y Friedberg, 1990: 75).

La connotación que deseamos resaltar es el espacio de dominación que adquieren los individuos por su pericia para el ejecución de una función concreta, al margen de la dimensión impositiva que proyecta el poder. Los sujetos investidos de esta autoridad legítima influyen en los demás para orientar de la mejor manera las tareas, lo cual queda validado por el acuerdo intersubjetivo de los actores que reconocen en esta autoridad la capacidad de dirección; el llamado "organigrama oficial" no produce la legitimación, sino el propio actuar de los sujetos y los elementos inherentes a su condición de experto dentro del ámbito de actuación en el que se desempeña.

La asimilación de la autoridad legítima es propia de los miembros de la organización por el acuerdo colectivo implícito de los individuos. La autoridad encauza las formas de conducta de otros en beneficio de las metas o intereses generales (Buckley, 1993: 257). La autoridad o el poder existen como espacio de dominación que repercute en la orientación colectiva de los sujetos que participan en un sector de la organización o en su totalidad. Tanto el poder que contiene la estructura formal como la autoridad legítima responden a un objetivo determinado o a un interés particular; sin embargo, en la organización sólo se legitima una acción cuando su contenido se encuentra inserto dentro de una función concreta.

La orientación de la conducta de la autoridad tanto en el pensamiento de Aristóteles como en el comportamiento administrativo está determinada por el reconocimiento colectivo; gracias a ello se le otorga a la autoridad el derecho de mando sobre ciertas acciones, fundado en la creencia de que las órdenes son una directriz 
objetiva de control vinculada con la función. En la autoridad queda establecido el derecho para determinar medidas, formular juicios sobre ciertas cuestiones o resolver controversias, o, de manera más amplia, para actuar como jefe o guía de otros hombres, enmarcado dentro de un orden social dado, como sucede en la organización; y se hace hincapié esencialmente en ese derecho y no en el poder, pues por sí solo el poder carece de legitimidad: ni el mayor tirano puede alcanzar ningún objetivo si no se reviste de autoridad, si no cuenta con un mínimo de validez que le permita emprender sus acciones (Maclever, 1966: 86). El consentimiento voluntario de los agentes es una cualidad de los sistemas de dominación en la autoridad para legitimarse, y en la organización se justifica, inicialmente, por la propia función.

La autoridad es la dirección o el control de la conducta de otros para la promoción de metas colectivas, basada en alguna forma discernible de consentimiento cognoscible de aquellos. Por lo tanto, la autoridad implica una sujeción informada y voluntaria, que es un estado psicológico definido, y una coordinación o identidad de las orientaciones hacia metas de los controladores y controlados. Según esta definición, la autoridad no es una forma especial de poder, ni el poder es un subtipo de autoridad (Buckley, 1993: 271). ${ }^{15}$

El concepto de autoridad significa que los integrantes asumen la condición de subordinados de una manera informada, es decir, con el reconocimiento pleno de que alguien más cuenta con mejores posibilidades de orientación para cumplir con las funciones. Gracias a esta conformidad cognoscible de los participantes es posible hacer referencia a la justificación de una forma de conducta. Así es como en este concepto de autoridad estamos en condiciones de comprender que los miembros de la organización asumen la directriz de los mandatos como un referente objetivo, informado y voluntario de dominación con lo que es posible apelar al acuerdo consensual para validar el comportamiento colectivo que sugiere la autoridad para el cumplimiento de las funciones. Mientras que en la dominación formal el consenso de los actores no es una necesidad debido a que el aparato normativo es suficiente para asumir el carácter dominante, en la comprensión de la autoridad constituye la esencia de su significado. La autoridad se caracteriza por el vínculo que se establece con los participantes en aras de alcanzar la cooperación plena, al margen de la jerarquía formal que sustenta el poder. La autoridad, como la hemos definido, se reconoce a partir de las acciones legítimas que conforman el actuar colectivo,

${ }^{15} \mathrm{El}$ subrayado es nuestro y las cursivas están en el original. 
en el cual el reconocimiento y la validez de los actos de autoridad fungen como catalizadores de la estabilidad de comportamiento de los participantes. Lo que subyace a la legitimidad, y por tanto a la autoridad, es la idea de comunidad que tiende a garantizar estructuras de funcionamiento con vistas a alcanzar un objetivo determinado.

La relación de mando y obediencia establece directrices de funcionamiento colectivo en las organizaciones y genera lineamientos de participación de los actores que aspiran a validar los actos de autoridad, en el sentido de fundar acciones recíprocas que permiten orientar el trabajo conjunto. La interacción de los individuos en las organizaciones aspira a establecer mecanismos adecuados de cooperación conjuntos, en los que si bien la autoridad funge como promotora del esfuerzo compartido, quienes concretan esta perspectiva de funcionamiento colaborador son los propios agentes dirigidos, que en un ámbito de legitimación de la autoridad se justifica por medio del reconocimiento de todos los actores; en este sentido, la subordinación adquiere una relevancia determinante en el significado de la autoridad porque gracias a ello es posible aspirar a la realización de las tareas por la aceptación voluntaria, informada y racional de los ordenamientos. Si una comunicación directiva es aceptada por el subordinado, se confirma o establece la dominación, lo que constituye su base de acción. La desobediencia a esa comunicación es para el subordinado una negación de la autoridad; por lo tanto, acatar una orden radica en las personas a quienes va dirigido el ordenamiento y no de la persona quien la emite, que es la persona dotada de mando (Barnard, 1971: 383). Si hablamos del concepto de poder, la desobediencia a una orden será motivo para que el dirigente condicione esa acción a la coercitividad del dominio para obligar a los actores a acatarla, en tanto si esa desobediencia se encuentra enmarcada en el concepto de autoridad que hemos definido, mientras sea la racionalidad de los sujetos lo que oriente esa decisión y no el mero acto de rebeldía, la carencia de legitimidad de la persona dotada de mando será la que explique ese hecho.

Independientemente de la posibilidad de que la aceptación de los mandatos estén condicionados por la utilización de la fuerza física, como caso extremo de validez para obligar a los actores a acatar una orden, o de su carácter legítimo, la dominación es creada y mantenida por la opinión pública (Robert Michels, citado por Barnard, 1971: 383), de ahí que sostengamos que la dominación es una atribución propia de quienes son dominados, en el sentido de que esta dominación corresponde a la forma de comportamiento que asumen los subordinados, especialmente si 
nos referimos a la legitimidad. Un sujeto acepta una comunicación por parte de la persona investida de mando cuando se cumplen cuatro condiciones simultáneamente: a) que entienda una comunicación; b) que en el momento de su aceptación crea que es congruente con el propósito de la organización; c) que en el momento de la aceptación crea que es compatible con su interés personal como un todo, y d) que sea capaz de acatarla mental y físicamente (Barnard, 1971: 384). Estos cuatro elementos en el proceso de mando y obediencia que indica Barnard constituyen los elementos primarios para comprender el significado de la autoridad en las organizaciones cuando se inserta en el ámbito de la legitimidad.

Una orden en el comportamiento administrativo es comprensible desde el momento en que el individuo es capaz de interpretarla con vistas a visualizar el sentido que propone una comunicación (Vid., Weber, 1999: 5 y ss), con lo que está en posibilidades de discernir si ese ordenamiento se enmarca dentro de un objetivo fijado de antemano mediante el contexto de significado en el que se halle, tanto individual como colectivo, así como la compatibilidad de las condiciones del subordinado con la tarea que se le encomienda. Una vez que la orden es asimilada, el subordinado acepta esta comunicación por las siguientes razones: porque constituye una posibilidad para ganar la aprobación y aceptación de los demás miembros; porque es capaz de contribuir a una causa que considera digna; por evitar posibles acciones disciplinarias; por cumplir con las normas morales, y por obtener recompensas (Terry, 1982: 334). Los elementos que se relacionan directamente con la legitimidad están referidas a las funciones de la organización que le permita atender los ordenamientos. En primera instancia diremos que el espacio de actuación de una autoridad está deliminado funcionalmente, de modo que responde a un ámbito de competencia al interior de la organización, dentro del cual se encuentra su comportamiento: una comunicación generada por una autoridad en la esfera organizacional que no responda a esta circunstancia carece de toda legitimación, incluso puede carecer de sentido en cualquier proceso de mando, mientras no sea propio de un sistema de objetivos establecidos; por ejemplo, carece de sentido en la organización el que a un subordinado se le ordene la compra de material para la construcción de la casa particular del jefe de vigilancia; o carece de legitimidad el que un jefe de finanzas ordene la manera en que debe fabricarse un tornillo en el departamento de producción. En este último caso, la persona investida de mando carece de autoridad para ordenar a los subordinados de otra área, porque su ámbito de competencia y de control es distinta a la establecida por la propia organización, además de que puede carecer de los conocimientos adecuados para esa función particular. Esto también conduce a la falta de incentivos del subordinado por acatar 
una orden, debido a que frecuentemente este tipo de circunstancias manifiestan una conducta autoritaria de las personas dotadas de mando.

Los alicientes que permiten a una persona acatar un ordenamiento son una consecuencia de la forma en que se ejerce una dominación, pues no es lo mismo que una persona realice una función cuando lo hace por el temor a las sanciones que cuando la tarea encomendada se ejecuta en un ambiente de cooperación y de consenso entre la autoridad y los subordinados, que tienda a la participación e interés común, que en el ámbito del comportamiento administrativo se trata de la consecución de un objetivo organizacional dentro de una perspectiva de validez de las acciones colectivas, conjuntamente con la perspectiva individual de los actores por asumir la responsabilidad ética en la ejecución del trabajo.

El contexto de significado es una determinante inicial para aspirar a la legitimación de la autoridad. En las organizaciones tanto las personas dotadas de mando como los subordinados asumen una condición particular dentro ellas, lo cual enmarca la participación de todos los actores. Gracias a esta disposición de objetivos organizacionales, la validez de las acciones responde a la delimitación funcional con base en la división del trabajo, misma que queda plasmada en la estructura orgánica mediante la distribución de puestos y la escala jerárquica que fija un ámbito de control, de acuerdo con un área de responsabilidad. No obstante, la formalidad que otorga la estructura orgánica no es un requisito para aspirar a la legitimación de una autoridad, pues la legitimidad de la autoridad está vinculada estrechamente con la experiencia, capacidad, inteligencia, conocimientos, valor moral o don de mando, la que ha sido definida por la teoría administrativa como la autoridad personal — autoridad legítima - que es diferente a la autoridad estatutaria (Vid., Fayol, 1969: 159 y ss.) - la que es propia de la estructura o como la denomina George Terry como la autoridad del puesto.

Con frecuencia, se reconoce que aunque el titular pueda tener una capacidad personal limitada, su consejo puede ser superior, por causa, tan sólo, de la ventaja de posición. Ésta es la autoridad de posición. Pero es evidente que algunos hombres tienen capacidad superior. Su conocimiento y su comprensión, independientemente de la posición, imponen respeto. Los hombres conceden autoridad a lo que ellos dicen en una organización, tan sólo por esta razón. Ésta es la autoridad de mando. Cuando la autoridad de mando se combina con la autoridad de posición, los hombres que tienen una conexión establecida en una organización, concederán generalmente la autoridad, aceptando órdenes muy 
alejadas de la zona de indiferencia. La confianza engendrada, incluso, puede hacer de la obediencia misma un incentivo (Barnard, 1971b: 391). ${ }^{16}$

La autoridad de posición, la autoridad estatutaria, en palabras de Fayol, o la autoridad del puesto, según la denominación de Terry, es la autoridad jerárquica o formal que debemos entenderla como el concepto de poder, debido a que su instancia de validez estriba en la posibilidad de coacción para hacerse obedecer. Barnard concede que la autoridad de mando, autoridad personal o autoridad legítima, corresponde a la dominación justificada en la función y en las cualidades personales de mando. El significado de la autoridad legítima en el comportamiento administrativo se puede entender como un individuo que es aceptado como autoridad por los demás miembros gracias a la personalidad, a la popularidad y a los logros pasados satisfactorios. Terry (1982: 335) señala al respecto lo siguiente: "El empleado que tiene una larga asociación con la actividad, conocimiento práctico de ella, más la competencia para exigir respeto y cooperación entusiasta, frecuentemente se encuentra con autoridad" ${ }^{17}$ Se trata del concepto de autoridad que se legitima por el reconocimiento intersubjetivo de todos los sujetos que colaboran en un ámbito funcional, referente a la capacidad moral para dirigir una función, dentro de la que se inserta la racionalidad de las acciones que son validadas por una colectividad, debido a que se reconoce que alguien más es superior en juicio y que es capaz de percibir algo mejor que uno mismo (Vid., Aristóteles, 2000c: 1325a y Gadamer, 2000: 45).

\section{Conclusión}

La idea del bien común en el pensamiento de Aristóteles es una referencia ineludible para comprender su concepto de autoridad. La acción individual no es una concepción aislada de los demás, sino que es una noción ética de significado para emprender las tareas necesarias en beneficio de la comunidad. El trabajo es la vinculación del hombre con la comunidad, de modo que no puede comprenderse la organización como un ente aislado de la comunidad, sino que responde a su espacio de significado, pues es ella quien define las necesidades que requiere para la subsistencia de sus miembros, independientemente de la necesidad creada por el mero consumo en la sociedad capitalista, se trata de generar satisfactores a la sociedad, por ello el bien común al que alude Aristóteles en su concepto de auto-

\footnotetext{
${ }^{16}$ Los subrayados se encuentran en el original.

${ }^{17}$ Los subrayados son nuestros.
} 
ridad constituye una fuente de explicación de la autoridad en el comportamiento administrativo, pues, en última instancia, la estipulación de los objetivos organizacionales responde a una necesidad social.

El trabajo coordinado no es posible comprenderlo sin un individuo que oriente la función. La autoridad adquirirá mayor legitimidad en su función si es capaz de dirigir mejor las actividades de los demás, porque el óptimo desempeño de ellos será un bien personal. Así, la autoridad en Aristóteles y la autoridad en el comportamiento administrativo se legitiman en los demás a partir de dos vertientes: por el referente comunitario, orientado al bien común, y por el reconocimiento informado, racional y voluntario que conceden los dominados por estar sustentado en la función, como un hecho objetivo de significado para legitimar los actos de autoridad. Apelar a la autoridad en el pensamiento de Aristóteles es asumir los actos virtuosos; es decir, reconocer que alguien más es mejor para orientar la función, porque dispone de los medios de orientación de la conducta más pertinentes para dirigir las acciones, cuyo sustento es la realización de la actividad que es propia de cada quien. Este concepto de autoridad en Aristóteles lo encontramos también dentro de la teoría administrativa, denominada como autoridad personal, autoridad moral o autoridad de mando, la cual se funda en la capacidad de dirección por el conocimiento de la función, la experiencia, la capacidad, el carisma y el don de mando.

El concepto de autoridad en el comportamiento administrativo se explica por el carácter legítimo de la relación de mando y obediencia que aspira a la cooperación plena de los subordinados, quienes asumen su condición de dominados de manera racional, informada y voluntaria por estar inmersa en el consenso informado, al margen de los elementos coactivos de dominio. En sí mismo, el concepto de dominación en el comportamiento administrativo explica la materialización del esfuerzo colectivo, mediante la orientación de las tareas organizacionales; sin embargo, la justificación racional del carácter dominante obedece a los procesos de legitimación que se producen en la relación social del mando y la obediencia. Independientemente de la estipulación formal o informal de la autoridad, la legitimidad de la autoridad descansa en el reconocimiento colectivo que se le otorga subjetivamente a un individuo para ejercer o dirigir una tarea; se trata de asumir la condición particular de ciertos agentes dentro de la organización para orientar mejor el sentido de una función que permita la consecución de uno o varios objetivos organizacionales. La autoridad legítima, que Mary Parker Follett (1995: 113) denomina como poder, es la capacidad que desarrolla el individuo a través 
de la experiencia, la inteligencia, el saber, el valor moral y el don de mando, en el sentido de que quien tiene la capacidad para dirigir cuenta con la legitimidad para ejercer la autoridad, así como el reconocimiento de los demás. La autoridad legítima es un hecho inherente a las propias acciones del individuo que apela al acuerdo consensual de todos los miembros para gestar en él la capacidad moral necesaria con el fin de asumir el liderazgo frente a los demás.

\section{Referencias}

Aristóteles (2000a). Ética Nicomáquea, versión de Julio Pallí Bonet, Madrid: Gredos.

(2000b). Política, versión de Antonio Gómez Robledo, segunda edición, México: Universidad Nacional Autónoma de México (edición bilingüe).

(2000c), Política, versión de Manuela García Valdés, Madrid: Gredos.

Barnard, Chester I. (1975). "Las funciones de los elementos dirigentes", en José, M. de Anzizu (comp.), Las funciones directivas, Barcelona: Labor.

(1971). "Teoría de la autoridad" en Harwood F. Merrill (comp.), Clásicos en administración, Tr. Aurelio Romeo del Valle, México: Limusa.

Buckley, Walter (1993). La sociología y la teoría moderna de los sistemas, Tr. Aníbal C. Leal, Buenos Aires: Amorrortu.

Crozier, Michel y Erhard Friedberg (1990). El actor y el sistema. Las restricciones de la acción colectiva, México: Alianza Editorial Mexicana.

Cruz Soto, Luis Antonio (2004). "Las fuentes de legitimidad de la autoridad", en Memoria del IX Foro de Investigación. Congreso Internacional de Contaduría, Administración e Informática. FCA, UNAM.

FAYOL, Henri (1969). Administración industrial y general, décimo primera edición, Tr. A. Garzón del Camino, México: Herrero Hermanos. 
Gadamer, Hans-Georg (2000). Verdad y Método, cuarta edición, Tr. Manuel Olasagasti, Salamanca: Sígueme.

Gallino, Luciano (1995). Diccionario de sociología, Tr. Stella Mastrangelo y Lorenzo Alegría, México: Siglo XXI.

Giddens, Anthony (1998). Capitalismo y la moderna teoría social. Un análisis de los escritos de Marx, Durkheim y Max Weber, Barcelona: Idea Universitaria.

Hall, Richard H. (1996). Organizaciones. Estructuras, procesos y resultados, sexta edición, Tr. Adolfo Deras Quiñones, México: Prentice Hall.

Maciver, Robert (1966). Teoría del gobierno, tr. Agustín Gil Lasierra, Madrid: Tecnos.

Mayntz, Renate (1974). "La estructura social", en Lecturas de administración, México: Universidad Nacional Autónoma de México.

Mary Parker Follett. Precursora de la administración (1995). editado por Pauline Graham, Tr. Carmen Aspe Solórzano, México: McGraw Hill.

PARSONs, TAlCotT (1997). "El aspecto político de la estructura y el proceso sociales" en David Easton (comp.), Enfoques sobre teoría política, Tr. José Rovira Armengol, Buenos Aires: Amorrortu.

Simon, Herbert (1979). El comportamiento administrativo, segunda edición, Tr. Amando Lázaro Ros, Buenos Aires: Aguilar.

Terry, George R. (1982). Principios de administración, nueva edición, Tr. Alfonso Vasseur Walls, México: CECSA,.

Villoro, Luis (2001). El poder y el valor. Fundamentos de una ética política, México: El Colegio Nacional-Fondo de Cultura Económica.

Weber, Max (1999). Economía y sociedad, segunda edición, Tr. José Medina Echavarría, et al., México: Fondo de Cultura Económica. 